\title{
London's nocturnal queer geographies
}

\author{
Ben Campkin and Laura Marshall
}

\author{
Why have London's LGBTQ+ nightlife venues been closing and what is at stake when they are \\ lost?
}

There are contradictory pulls in neoliberal cities. On the one hand there has been an acceptance of mainstream Lesbian, Gay, Bisexual, Trans and Queer (LGBTQ+) identities, as celebrated for example through commercially sponsored and officially endorsed Pride rallies. On the other, real estate-led global city competitiveness is affecting our capacity to secure the heritage of queer publics, and for them to keep a foothold in the spaces they have historically occupied. Internationally, researchers are charting the effects of gentrification on neighbourhoods associated with LGBTQ+ communities. In the UK, since LGBTQ+ rights have been won in large part through European Union-led legislation, the trajectory of an increasing liberalisation of attitudes and legal protections is not guaranteed. Recent data shows losses of a wide range of cultural and social spaces, but the provision of LGBTQ+ nightvenues has suffered an even more dramatic fall than has been seen for pubs in the UK overall; and LGBTQ+ night-venues have suffered disproportionately in London's wider losses of nightclubs and grassroots music venues, as they have been rapidly succumbing to commercial residential and infrastructure-led developments. If pubs, generally, are important to the social life of neighbourhoods, LGBTQ+ venues function as vital infrastructure for these groups, providing spaces of care and community against wider contexts of oppression and violence. In London, as in other cities internationally, increasing attention is being paid to LGBTQ+ heritage alongside that of other minority groups. But are these efforts in vain, given that they are up against the forces of urbanisation and the ever-deeper financialisation of urban centres?

\section{Queer cultural infrastructure}

During 2016 there was extensive media and public discussion of threats to the night-time venues serving London's LGBTQ+ communities, prompted by a spate of closures. In response, London's mayoral candidate and later mayor, Sadiq Khan, emphasised his commitment to preserving the capital's LGBTQ+ spaces, and positioned himself as an advocate for LGBTQ+ communities. Since he has been in office Khan has appointed a new Night Czar, Amy Lamé, with whom he has marched at the front of London Pride; and the Greater London Authority (GLA) Culture Team have included LGBTQ+ spaces in their work on London's social and cultural infrastructure, in order to shape plans and policies to protect and sustain it.

By 2016, activism around threats of closure had prompted the formation of Raze Collective, a charity representing LGBTQ+ performers, and Queer Spaces Network (QSN), which brings together activists and community members with an interest in preserving and supporting spaces for the LGBTQ+ community. But there was very little evidence about exactly what was happening, or why. Working with these groups we therefore set about designing a research project to map LGBTQ+ nightlife spaces in the capital. ${ }^{1}$ What did the profile of London's LGBTQ+ scenes and spaces look like? Which factors were driving closures and ongoing threats to venues? How had this impacted London's LGBTQ+ communities? In addressing these questions, we decided it was necessary to cast our attention back to 1986 - when the Greater London Council was disbanded, marking a shift in urban 
regeneration policy towards the neoliberalism that remains dominant, and has so damaged the fabric of London life.

Our research quickly produced strong evidence for the importance of nightlife spaces to community life and wellbeing. It highlighted the diversity of the capital's LGBTQ+ nightlife as a valuable contributor to neighbourhoods, the night-time economy and culture. And it produced the first concrete evidence of the recent intensity of closures, as well as the significant impacts on the longest standing and most community-valued venues. It also became apparent that the - relatively few - spaces run by and for women and Black, Asian and Minority Ethnic (BAME) LGBTQ+ people had been disproportionately vulnerable to closure.

Alongside other work on pubs, grassroots music venues and nightclubs in general, the GLA's interest was in assessing the trends of openings and closures of LGBTQ+ venues in order to identify opportunities and challenges related to what it has designated as London's 'cultural and social infrastructure'. ${ }^{2}$ In this endeavour, London civil servants have forged alliances with specific campaign groups, including Raze and QSN, to develop evidence to underpin Khan's forthcoming Cultural Infrastructure Plan for London.

\section{Queer facts, queer figures}

The GLA - and journalists - were mainly interested in the headline figure for the drop in LGBTQ+ venue numbers. Statistics make good headlines and have strong currency when it comes to making policy decisions on politicised issues. Quantitative data wields clarity and clout. But this focus on headline figures often has the effect of shifting attention away from more nuanced accounts, and of misrepresenting or erasing important factors that have an impact on the most marginalised members of LGBTQ+ communities. And a response that overlooks these complexities is likely to repeat and reinforce the fundamental power asymmetries and injustices that feature strongly in processes of urban change.

With this in mind, when the community groups and GLA emphasised what they wanted was essentially a counting exercise - how many licensed premises were there now, compared to then? we insisted on approaching this quantitative exercise, queerly. We wanted to combine data on the number and location of venues with a variety of qualitative evidence: surveys, ephemera from archives, online and offline listings, public workshops, detailed case studies of long-running, closed and extant venues, and so on. We felt that this was essential in order to pay close attention to intersectional identities and varied experiences, and therefore to represent the asymmetrical social and spatial power dynamics at play within London's LGBTQ+ communities.

Surveying community members, as well as performers, producers and venue owners and operators, was essential to understand how these groups perceive the role of LGBTQ+ night-spaces, the impacts of closures, and what the responses should be. We therefore asked respondents to selfdescribe demographic characteristics, and this resulted in a powerful illustration of the diversity of expressions of sexuality, gender, ethnicity, abilities, socio-economic background and other variables through which people identify. Analysing the responses also brought the impact of venue closures, and threats of closure, into sharp relief. The narratives expressed wide-ranging anxieties, driven by a sense of threat to individual and community heritage and wellbeing; people were anxious about the loss, or potential loss, of spaces that had embedded within them the histories of LGBTQ+ struggles; and they told us of their own personal histories of coming out and establishing social ties. These anxieties were often linked to a perception that London is losing distinctiveness, as heterogeneous minority cultures are being diminished. Such insights into individual experiences counterbalance boosterist 'global cities' discourses that promote celebratory visions of London as a city with thriving LGBTQ+ communities and spaces, narratives which are particularly conspicuous during Pride.

\section{Losing 'safe' spaces}

When people expressed concern for the harm caused by the loss of venues they frequently referred to 'safe spaces', and this concept was articulated in various ways. Commonly, respondents described spaces that enabled safety in self-expression; that provided a sense of security, community and belonging; that allowed them to find or to be with friends; and that offered them protection from forms 
of harassment, discrimination, threats and violence, as experienced in a cisheteronormative world. Safe spaces were prized as being open, non-threatening, refuges, inclusive, pockets within safe neighbourhoods, and spaces free from cisheteronormativity, or as places where normative assumptions, values and practices were challenged. Examples of ways in which this feeling of safety was manifested included being able to use gender neutral bathrooms or gendered bathrooms without having one's gender questioned; not feeling 'other'; and feeling safe within groups of people with shared experiences and respect for differences. Respondents referred to 'havens' or 'substitute homes'.

Survey respondents reported that venue closures had had negative effects on mental health and emotional wellbeing, especially in relation to people's sense of identity and community. Terms chosen to describe the closures were consistently strong, conveying intense anxieties: 'erasure', 'erosion', 'devastation', 'ostracization', 'stigma', 'the world closing down', a fear that people were being pushed 'back into the closet'. Some individuals stated that LGBTQ+ venues, specifically those local to them, were the main spaces in London where they felt a sense of belonging. Since venues had been disappearing without being replaced, closures were commonly seen as forcing LGBTQ+ people to live less social, less public, lives, and this was having the most impact on already marginalised groups within the LGBTQ+ communities, for example in eliminating spaces for women.

The importance of LGBTQ+ nightlife spaces for experiencing and participating in performance, art, music, film, fashion and other creative forms, especially those specific to LGBTQ+ cultures, such as drag, was also strongly emphasised. Venues were noted as platforms for performers, with closures highlighted as threatening the potential and development of new and established artists. The role of London as a national and international exemplar of thriving LGBTQ+ culture and community, with a large LGBTQ+ population, was also cited, with respondents feeling that the capital should be a positive example in how LGBTQ+ venues and cultures can and should be supported.

\section{Re-orienting LGBTQ+ nightlife towards communities}

Respondents were overwhelmingly positive about the value of LGBTQ+ nightlife space to themselves, their communities and London broadly. It is however, vital to understand that LGBTQ+ is not synonymous with gay, and gay bars are not necessarily inclusive or accessible to all members of gay communities, let alone LGBTQ+ communities. Discussion on venue closures - and this was reflected in the comments we received - has foregrounded criticisms of mainstream models of nightlife, highlighting the lack of spaces for women, trans people and people of colour, and observing how racism, classism, ableism, sexism, transphobia and homophobia can be built into nightlife, which often operates through exclusions. Respondents to our survey were particularly concerned about: an over-dominance of cis gay men across LGBTQ+ spaces, and the privileging of white, hypermasculine, muscular male bodies within these spaces; the centrality of alcohol, drinking culture and recreational drug use; normativity and homonormativity in gay venues; loud music and crowds; prohibitive prices; and a lack of venues outside Zone 1. It is notable that in current scenes there are a number of emerging events - if fewer formal, licensed premises - that are intentionally setting out to address such criticisms and include otherwise excluded groups.

Several respondents who commented on the 'gay scene's' commercial focus felt that it was geared towards middle-class audiences, and was often exclusionary because of its economic profile or other forms of standardisation and discrimination. In particular, Soho was associated with commercial, unfriendly and 'sanitised' forms of LGBTQ+ nightlife. In a number of instances this was pitted against community-oriented nightlife, sometimes associated with earlier periods. Such critiques of the commercial scene(s) also existed in the 1980s. As in the 1980s, alongside these criticisms, there is a strong appetite amongst community members, venue owners, performers and promoters to protect sites of LGBTQ+ heritage, and create and nurture nightlife spaces that respond to Londoners' sexual, gender and ethnic diversity. 
'These venues are not re-opening somewhere else. We're losing them altogether, and for me that is the most alarming. Where will we go?'

'Closure makes me depressed. We fought so hard in the "70s for our rights, and here in London were blessed with the open manifestation of these rights in our bars and clubs."

'Something in the community dies with every closed door'

'Loss of community and the sense of shared ownership, shared experience, is devastating to marginalised individuals and groups.'

'If there are less places for queer people to connect and socialise on a normalised level, stigma returns and pushes the marginalised further into the margins and shadows.'

'Closures make the city less welcoming and less accessible for queer people'

'Having a safe and unprejudiced place to socialise and have fun is important for my mental health and wellbeing.'

'LGBT spaces provide a safe space for people to socialise, free from fear of harassment and discrimination.'

'[The] LGBTQI community still need safe places where they can connect with each other. LGBTQI people are still closeted, feel isolated and are discriminated against and LGBTQI nightlife spaces give the community a place to feel safe, express their sexuality freely and openly.'

Why LBGTQ+ spaces are so important, extracts of responses to our 2016 survey

These critiques of London's LGBTQ+ nightlife and community responses to exclusion and accessibility have implications for the ways in which the current provision of LGBTQ+ spaces is understood, including by planners and local authorities. For example, spaces benefit particular communities in ways that are not equally inclusive to all within LGBTQ+ communities. Thus in Hackney between 2006 and 2017 there was no net loss of venues, yet this period saw closures of venues specifically for women and openings of, often gay male-dominated, LBGTQ+ venues. Such context behind the numbers gives vital insights into intra-community power dynamics, showing that venues are not simply interchangeable, or easily replaced.

\section{Mapping queer night-space}

When we looked closely into the histories of specific venues, we were confronted with a wide range of formats, highlighting the dynamic profile of queer nightlife and - in spite of the recent spate of closures - its striking resilience and adaptability. Organisational and ownership models varied from socialist cooperatives and collaborative community enterprises to the entrepreneurial models that have become dominant over the years. Since the 1980s, LGBTQ+ nightlife has inhabited a variety of spaces, too, often involving imaginative re-use of the everyday and infrastructural urban fabric. We observed community centres, cinemas, bars, pubs, clubs, cafes, restaurants, hotels, saunas, bookshops and theatres, and we noted how existing spaces, from town halls to shopping malls, had been appropriated to create night-spaces for these communities.

Mapping venues over time we were also able to chart geographical swells, ebbs and flows in LGBTQ+ nightlife spaces, emphasising distinctive historical and present-day clusters, including Earls Court and Shepherd's Bush during the 1970s and 1980s; King's Cross and the Angel in the 1980s and 1990s; Soho from the 1990s until the present; Vauxhall from the late 1990s and early 2000s; east London from the 2000s; and, since the 2010s, a rise in events in south-east London, an area with a scene during the 1970s and 1980s that had since declined. 
We identified a total of 158 LGBTQ+ venues during the period from 2006 to 2017 . The peak was in 2006, when 121 venues were operating, and the low was in 2017, when 51 venues were operating. We therefore calculated a net loss of 58 per cent of venues. The number of venues had risen steadily from 1986 to 2001, before dropping slightly and then peaking in 2006. But since then - with the exception of 2008 - numbers fell year on year until 2017. ${ }^{3}$

Our 2006-17 data illustrated smaller clusters, as well as individual venues in many neighbourhoods across London. Maps produced from this data by the GLA showed the net loss of venues by borough, comparing the relative density by year. Boroughs such as Camden and Tower Hamlets, which started in 2006 with higher densities (>11) had lower densities by 2017; and by 2016 only Westminster and Lambeth had venue counts greater than 11 . There were ten boroughs with no recorded LGBTQ+ venues in 2006, and nineteen in 2016. In some cases, although only a very small number of venues had been lost, these losses were nonetheless significant, as highlighted by qualitative evidence gathered. This was either because they had important community, historic and neighbourhood functions, or because they served otherwise underserved client groups, women for example.

The significant drop in LGBTQ+ venues is particularly alarming when seen alongside other recent data. According to Metropolitan Police data, homophobic hate crime in London spiked 20 per cent following the Brexit referendum and rose by 11 per cent over the year to July $2018 .{ }^{4}$ Furthermore, research indicates that LGBTQ+ people experience higher rates of mental ill health than the rest of the population. ${ }^{5}$ Stonewall have also identified barriers to LGBTQ+ people accessing healthcare - a context of exclusion which indicates the fundamental role played by communal spaces that are deemed safe spaces by LGBTQ+ communities, as our survey emphasised. ${ }^{6}$ Our research suggests that the number of non-commercial and community-oriented daytime spaces in London has also diminished - two notable examples are First Out café and PACE, a mental health service for LGBTQ+ people that closed in 2016 after 31 years of operation, due to local authority funding cuts. ${ }^{7}$

We counted 25 non-LGBTQ+ venues that regularly host LGBTQ+ events, which is inevitably an underestimation since this is not a type of space that we have actively gathered data on. Nonetheless, non-LGBTQ+ venues that regularly host LGBTQ+ events are increasingly prevalent and valuable as LGBTQ+ venues close. Survey respondents attached importance to queering 'straight' venues, whilst recognising that non-LGBTQ+ venues cannot replace permanent LGBTQ+ venues or replicate the wellbeing and social functions that full-time spaces have provided. The trend of LGBTQ+ communities being hosted within non-LGBTQ+ venues certainly highlights growing levels of social acceptance. However, further research is needed into how venues accommodate specific needs. Activist and cultural producer Chardine Taylor-Stone has documented the reality of producing events in nonLGBTQ venues, despite their desire to host LGBTQ+ nights: as a black lesbian, and putting on events for audiences of 'Femmes, Dykes, Twinks, Queens and Queers', she often has to confront gendered, sexualised and racialised assumptions and prejudices. ${ }^{8}$ Seeing this trend as a wholly progressive story of social acceptance thus erases forms of intersecting oppression experienced by members of specific LGBTQ+ communities. A further complicating factor is that non-LGBTQ+ venues have also been in decline.

Although London's LGBTQ+ communities are diverse in sexuality, gender, ethnicity, nationality, disability, class and age, our research highlights an enduring predominance of venues owned by and serving a majority clientele of white, cisgender, non-disabled, middle-class men. Indeed, only one currently operating LGBTQ+ venue, VFD in Dalston, was found to be leased and run by a person of colour. It is clear that LGBTQ+ women and BAME communities have been disproportionately vulnerable to closures: there has been a rather steep decline in women's venues, and there is a relative absence of spaces run by and for BAME people in LGBTQ+ communities. No licensed premises oriented specifically toward trans communities were recorded. However trans-inclusive venues and nights specifically for trans-and non-binary people have long existed and are increasingly evident across LGBTQ+ venues. Burgeoning events and scenes run by and for queer, trans and intersex people of colour have to be seen against the complete lack of full-time, formal, licensed venues operated by and predominantly for members of these communities in London. 


\section{What has been driving venue closures?}

We found multiple contributing factors for the closures. One major factor has been the impact on neighbourhoods of large-scale transport projects, as well as development of smaller-scale residential and mixed-use sites. For example, six LGBTQ+ venues closed in association with the Crossrail station development at Tottenham Court Road, as did the London Astoria, which previously used to host weekly LGBTQ+ events over a long time span. A link can also be drawn between the redevelopment associated with the King's Cross and St Pancras Channel Tunnel Rail Link and the more gradual closure of bars in King's Cross and Angel, an area where there was a notable cluster of nightlife and civic spaces in 1980s and 1990s London.

Some of these closures were directly linked to the state-facilitated and developer-led regeneration of King's Cross Central, but other closures were the result of more indirect factors associated with gentrification, such as less availability of space and higher rents. However, the opening of the East London Line extension of the London Overground in 2010 has served thriving and new spaces, and contributed to the factors enabling spaces to open in previously underserved neighbourhoods. Such developments, of course, have also caused direct or indirect pressures on other potential users of the neighbourhood, through rent increases and the diminishing availability of space. There is clearly a hierarchy of desirable spaces: new users displace existing ones in waves, as property values increase in circles that spread out from the centre. The development of transport infrastructure plays a crucial role in these processes.

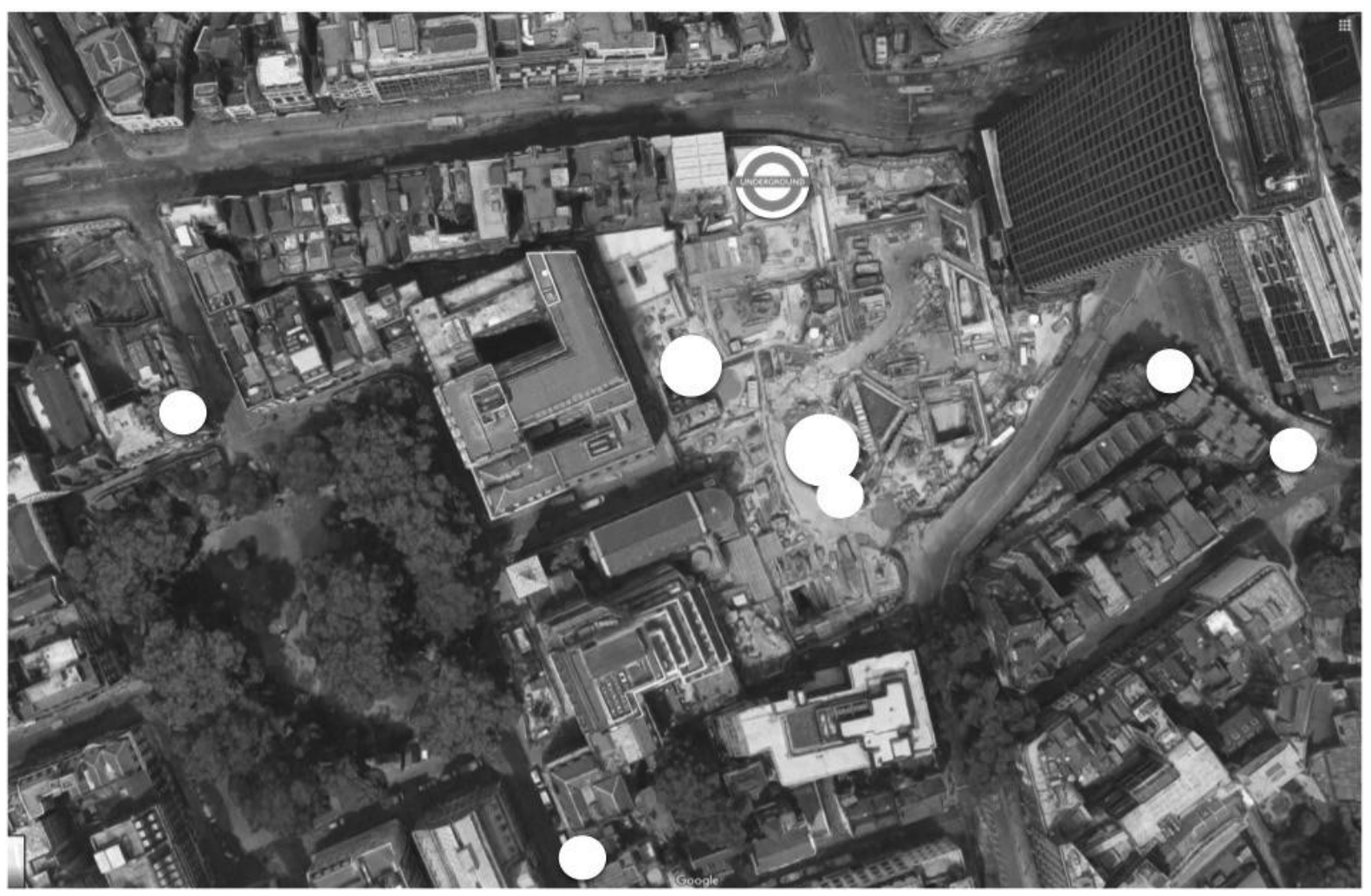

Closed venues since 2006 around Tottenham Court Road Station, UCL Urban Laboratory, 2017

The increasing desirability of a neighbourhood and the associated value of development are key factors in the context of a built environment that has become intensely commodified, to the point where most social and cultural venues struggle to find affordable space. A number of such property developments have been strongly opposed, with varying outcomes, by local and wider LGBTQ+ communities. In 2017, Tower Hamlets council placed planning conditions on developers Regal Homes, stipulating the re-provision in the new development of a LGBTQ+ nightlife space of equivalent size to the soon-to-be-demolished Joiners Arms. A lack of implementation of safeguarding measures in the existing planning system has in the past proved detrimental to venues and venue clusters, but this sets a new precedent; and these conditions, a first in UK urban planning, were hard-won by 
campaign group Friends of the Joiners Arms. Across the city, at Soho's The Yard, after a series of planning applications were submitted for a residential development in 2014 and 2015, a high profile and successful campaign was set up to 'Save the Yard'. One of the applications attracted 416 public comments, with 395 objections. These objections provided detailed narratives explaining the value that LGBTQ+ people associate with the venue. Yet the venue's operator and campaigners were forced to oppose multiple, closely similar, planning applications.

The sale and change of use of property by landlords, and suddenly enforced rent spikes, have proved to be key factors in closures. In these cases, venue owners, operators, clients and campaigns have severely limited negotiating power, coming up as they do against the large organisations leading developments, such as large pub companies, property owners, offshore investors and developers. The accumulated power of companies with multiple land and venue holdings far outweighs that of individual operators. In a number of cases, operators have been unaware of who it is that owns the freehold of buildings, because of complex layers of ownership, mediated by agents. Such opacity limits the capacity of communities, customers and operators to respond effectively when development proposals are tabled. High-profile cases - such as iconic cabaret spaces The Royal Vauxhall Tavern and The Black Cap - demonstrate how a lack of transparency about financial arrangements and lines of ownership pose significant risks for operators and community members in negotiating for spaces to remain open, or to be reopened when already closed.

It is worth noting that the number of venue closures linked to business-related financial issues (as opposed to external factors) was low (approximately 6 per cent of the instances of closure that we investigated), but this may have been a reason for other closed venues, since in a quarter of cases this information was not available in the public domain. Nonetheless, it is notable that venues like The Black Cap and the Joiners Arms were operating as successful and popular businesses before they were closed due to developers' plans.

It is difficult to match trends in provision and closure to specific phenomena, and our case studies demonstrate that closures must be understood through attention to particular circumstances. However, it is also evident that the shape of provision of LGBTQ+ venues has to be understood within the wider context of the neoliberalisation of strategic planning. A better understanding on closures can be attained by paying attention to the changing landscape of government, mayoral and local government agendas and policies, which shape London's property market and specific forms of development, and have an impact on permitted development, housing and infrastructure. Since the GLC was closed down in 1986 there has been a shift away from more favourable conditions for running LGBTQ venues - and in particular for community-focused venues. And in recent years even long-established venues are finding it difficult to operate, or are succumbing to development aimed at the maximisation of profit from a plot or building. The significant drop in the number of venues, and the closure of long-standing venues in the later 2000 s, must be understood in relation to a configuration of conditions that includes: the banking crisis of 2008 and an associated period of economic instability; the austerity programme of the Conservative-led coalition government (20102015), launched in 2010; and the same government's overall loosening of the planning system in favour of development.

At the London level, sustainability analysts have noted that Boris Johnson's tenure as Mayor of London (2008-16) was a period during which the strategic policy focus on sustainable development subsided, and there were fewer specific requirements on developers for social sustainability, community and local economic support. ${ }^{9}$ The revised London Plan (2011) had a more explicit focus on economic growth and welcoming development, a rhetorical emphasis on the minimisation of local government and process, and a focus on the delivery of major transport infrastructure projects including the 2012 Olympic Games. ${ }^{10}$ Simultaneously, there have been extensive cuts to local authorities' budgets under the fiscal austerity agendas of both the Coalition and succeeding Conservative governments. These phenomena should be set against an overall longer-term shift, from the 1980s to the present, in the concept and practice of regeneration towards a real estate, property-led approach, which replaced the more community-centred plans supported by the Greater London Council in the 1980s. As noted by David Byrne in the last issue of Soundings, shifts towards property-led regeneration have profoundly reshaped local politics, including the quotidian operations 
of urban governance, with negative impacts on social and cultural diversity that have been widely critiqued. ${ }^{11}$

Following the publication of data from the research we have been discussing, the Mayor, GLA and some local authorities have been responding to closures and pressures on LGBTQ+ venues through practical and policy measures. Having partially funded the research, the GLA have cited the evidence we produced in their Draft London Plan - which is subject to an Examination in Public at the time of writing - and in their Culture and the Night-time Economy Supplementary Planning Guidance, and it will inform the forthcoming Cultural Infrastructure Plan. They have also launched an LGBT+ Venues Charter and an LGBT+ Venues Forum, and they have committed to an annual audit of LGBTQ+ venues. ${ }^{12}$ These mechanisms, intended to protect and support the capital's LGBTQ+ nightlife, are reflected in the priorities and activities of Amy Lamé in her Night Czar role. However, the lasting impact of these new measures remains to be seen. The GLA's power is limited by their remit, since planning and licensing policy and decisions are implemented at a borough level. There are some grounds for optimism though: recent events, including the success of the Friends of the Joiners Arms in Tower Hamlets, show the potential of borough councils to protect against closures and ensure the re-provision of valued LGBTQ+ spaces threatened by private developments.

Bolder moves could certainly be made at borough and city levels to counter the damaging effects of urban regeneration and gentrification processes upon LGBTQ+ communities. Multiple and overlapping forms of bias and discrimination are experienced, across a variety of spaces, by a wide range of different groups and individuals, including discrimination on the grounds of sexuality, gender, ethnicity, class, abilities, age and faith. ${ }^{13}$ This means that a sensitivity to intersectionality and diversity within LGBTQ+ communities is especially important in planning and licensing decision-making, as well as support for culture, health and welfare. The US city of Philadelphia has an Office of LGBT Affairs, which advocates for LGBTQ+ issues in all areas of city government, and is a permanent part of the city's charter. This is a bold and successful model that could be productively replicated in other cities and boroughs. Establishing such an office in London could comprehensively integrate policy and practice, and aim to address all the issues that have an impact on the lives of LGBTQ+ Londoners; and it would also protect the legacy of Khan and Lamé's commitments to LGBTQ+ Londoners beyond their tenures at City Hall.

Our research has pointed to the profound ways in which LGBTQ+ night spaces have, in the mayor's terms, provided 'social and cultural infrastructure' to support these communities. They do not, of course, exist in a vacuum, and, like other nightlife and cultural spaces, the venues that we have studied contribute powerfully to the neighbourhoods where they are located, as well as to the wider social life of the city and the 'night-time economy' - which is what drives the attention to night-space by Khan and mayors in other cosmopolitan cities. Although these venues serve specific needs, for particular groups, the threats to them must be seen alongside other contemporary public conversations: on gentrification and regeneration; and on the role of culture and heritage in promoting social inclusion, diversity, the provision of safe space, and places where minorities can choose either to assimilate or to assert their difference. At a time of rising inequality and intense competition for space for social and cultural life, venue closures have already had a huge impact on vulnerable minorities.

Ben Campkin is Professor of History and Theory of Architecture and Urbanism at University College London and the author of Remaking London: Decline and Regeneration in Urban Culture (I.B. Tauris 2013).

Laura Marshall researches urban geographies of gender and sexuality as a research assistant at the UCL Urban Laboratory and doctoral candidate at the Bartlett School of Architecture and Department of Geography, University College London.

\section{Notes}

1. See B. Campkin and L. Marshall, LGBTQI Nightlife in London: From 1986 to the Present, UCL Urban Laboratory, 2016; B. Campkin and L. Marshall, LGBTQ+ Cultural Infrastructure in London, Night Venues, 2006 - present, UCL Urban Laboratory, 2017. These publications are open access and available at www.ucl.ac.uk/urbanlab/research/lgbtqi-space. 
2. In line with a UK-wide trend, the number of pubs in London the UK fell by 25 per cent from 2001 to 2016; the number of grassroots music venues in London has dropped 35 per cent since 2007, and nearly 50 per cent of the UK's nightclubs closed from 2005 to 2015. See M. Wickham \& N. Cominetti, 'Closing Time: London's Public Houses', GLA Economics, Current Issues Note 53, April 2017; GLA, 'Saving London's Music Venues', Greater London Authority website 2017:

https://www.london.gov.uk/what-we- do/arts-and-culture/music/saving-londons-music-venues; N. Baker, 'Half of UK Nightclubs Closed since 2005', The Drinks Business, 10 August 2015: www.thedrinksbusiness.com/2015/08/half-of-uk-nightclubs-closed-since-2005/.

3. There were notably sharp falls in 2007 (23 venues), 2009 (17 venues), and 2016 (11 venues). See our LGBTQ+ Cultural Infrastructure in London.

4. Metropolitan Police, Hate crime or special crime dashboard, Metropolitan Police Stats and Data 2018: www.met.police.uk/sd/stats-and-data/met/hate-crime-dashboard/.

5. N. Nadin, E. Peel, A. Tyler and I. Rivers, The RaRE Research Report: LGB\&T Mental Health Risk and Resilience Explored, 2015; National Institute of Mental Health in England, Mental disorders, suicide, and deliberate self harm in lesbian, gay and bisexual people: a systematic review, 2007; I. Meyer, 'Prejudice, social stress, and mental health in lesbian, gay, and bisexual populations: conceptual issues and research evidence', Psychological bulletin 129.5, 2003; G. Henderson and J. Varney, 'Mental health challenges within the LGBT community', Public Health England, 2017: www.publichealthmatters.blog.gov.uk/2017/07/06/mental-health-challenges-withinthe-lgbt-community/.

6. A Guasp and J. Taylor, Experience of healthcare: Stonewall health briefing, 2012: www.stonewall.org.uk/sites/default/files/Experiences_of_Healthcare_Stonewall_Health_Briefing_ 2012 _.pdf.

7. N. Duffy, 'LGBT+ mental health charity PACE shutting down after 31 years', Pink News, 2016: www.pinknews.co.uk/2016/01/22/lgbt-mental-health-charity-pace-shutting-down-after-31-years/.

8. C. Taylor-Stone, 'They only want us when we are not there', in B. Campkin, R. Ross and L. Marshall (eds), 'LGBTQ+ Night-time Spaces: Past, Present \& Future', Urban Pamphleteer \#7, 1718, 2018.

9. N. Holman, 'The changing nature of the London Plan', in Kath Scanlon and Ben Kochan, (eds), London: Coping With Austerity, London School of Economics and Political Science, 2010; M.

Raco, 'Privatisation, managerialism and the changing politics of sustainability planning in London', in R. Imrie and L. Lees (eds), Sustainable London?: The Future of a Global City, Polity Press, Bristol 2014.

10. A. Wilson, 'New roles for urban models: planning for the long term', Regional Studies, Regional Science, 3:1, 48-57, 2016; L. Lees, H. Shin and E. Lopez-Morales, Planetary Gentrification, Polity Press 2016.

11. See D. Byrne, 'The problem that is Labour local government', Soundings 69, Summer 2018, 50-61(12).

12. GLA, 'LGBT+ nightlife venues', Arts and Culture, Greater London Authority, 2018:

www.london.gov.uk/what-we-do/arts-and-culture/lgbt-nightlife-venues.

13. K. Crenshaw, 'Demarginalizing the Intersection of Race and Sex: A Black Feminist Critique of Antidiscrimination Doctrine, Feminist Theory and Antiracist Politics', University of Chicago Legal Forum, No. 8, 1989; P.L. Doan (ed), Planning and LGBTQ Communities: The Need for Inclusive Queer Space, Routledge 2015; C. Irazábal and C. Huerta, 'Intersectionality and planning at the margins: LGBTQ youth of color in New York', Gender, Place and Culture, 23:5, 2016. 